- Original Article

\title{
Detecting Peripheral Arterial Disease in Primary Care: A Population Based Study
}

\author{
Tolga Vural' ${ }^{1}$ Makbule Neslişah Tan ${ }^{2, *}$, Mehtap Kartal ${ }^{2}$, Azize Dilek Güldal ${ }^{2}$ \\ ${ }^{1}$ Incirliova Family Health Center, Aydın, Turkey \\ ${ }^{2}$ Department of Family Medicine, Dokuz Eylul University School of Medicine, Izmir, Turkey
}

Background: Peripheral arterial disease (PAD) can progress silently without any clinical symptoms. Ankle-brachial index (ABI) is the recommended method used in primary care. We aimed to determine the prevalence of PAD and its related risk factors in primary care.

Methods: In this cross-sectional study, 250 participants aged $\geq 45$ years were recruited randomly from the registered patients of family health center in a district of Izmir, Turkey. Patients' demographic data, PAD symptoms, and PAD risk factors were obtained. The $\mathrm{PAD}$ group consisted of patients with $\mathrm{ABI}$ levels $<0.9$; the non-compressible artery (NCA) group consisted of patients with ABI levels $>1.3$.

Results: The prevalence of PAD was $17.6 \%$ (22.5\% in women and $11.1 \%$ in men), while that of NCA was $15.2 \%$ (12.7\% in women and $25.0 \%$ in men). About $27.3 \%$ and $54.5 \%$ of patients with PAD did not have claudication and problems with walking distance, respectively. Of the NCA patients, $15.8 \%$ had problems with walking distance and 39.5\% had claudication. Regression analysis revealed two predictors of PAD (age $\geq 65$ years: odds ratio [OR], 3.51; 95\% confidence interval [CI], 1.65-7.47; claudication: OR, 3.41; 95\% CI, 1.58-7.39) and three predictors of NCA (age <65 years: OR, 2.55; 95\% CI, 1.01-6.45; male sex: OR, 2.40; 95\% CI, 1.10-5.25; triglyceride [TG] >200 mg/dL: OR, 4.11; 95\% CI, 1.58-10.67).

Conclusion: PAD had a prevalence of $17.6 \%$ and was associated with age $\geq 65$ years and claudication. NCA had a prevalence of $15.2 \%$ and was associated with age $<65$ years, $\mathrm{TG}>200 \mathrm{mg} / \mathrm{dL}$, and male sex.

Keywords: Ankle Brachial Index; Peripheral Arterial Disease; Primary Health Care; Risk Factors

Received: May 17, 2018, Revised: June 30, 2018, Accepted: July 19, 2018

*Corresponding Author: Makbule Neslişah Tan https://orcid.org/0000-0002-3262-7815

Tel: +90-2324124961, Fax: +90-2324124959, E-mail: drnesli293@hotmail.com 


\section{INTRODUCTION}

Peripheral arterial disease (PAD) is a progressive disease resulting in narrowing and blockage of the vessels. ${ }^{1)} \mathrm{PAD}$ is a common condition with an associated morbidity and mortality. If it is left untreated, it can increase the risk of heart attack, stroke, amputation, and death. ${ }^{2)}$ Moreover, the clinical symptoms of PAD such as intermittent claudication, arterial ulcers, necrosis, and gangrene can greatly reduce patients' quality of life. ${ }^{3)}$ Several diseases and conditions, including advanced age, smoking, diabetes, hypertension, hyperlipidemia, male sex, and elevated blood glucose, are considered as risk factors of $\mathrm{PAD} .^{2)} \mathrm{A}$ low ankle-brachial index (ABI) level is an important indicator of atherosclerosis, but only $20 \%$ of the patients who have ABI level $<0.90$ develop symptoms. ${ }^{3)}$ Therefore, PAD is currently considered as a subclinical disease, which can progress silently. Due to this fact, PAD must be diagnosed in primary health care centers. ${ }^{3)}$

In the United States, the prevalence of $\mathrm{PAD}$ is $2.5 \%$ in patients aged between 40 and 59 years, $8.3 \%$ in those aged between 60 and 69 years, and $18.8 \%$ in those aged between $70-79$ years. ${ }^{4}$ A prevalence study conducted in the Netherlands showed that the prevalence of PAD increases with age, and $19.1 \%$ of the PAD patients were aged over 55 years. ${ }^{5)} \mathrm{PAD}$ prevalence was reported to be $19.76 \%$ and $20.0 \%$ in two different studies conducted in Turkey. ${ }^{6,7)}$ Although the number of studies in Turkey focusing on PAD prevalence are increasing in the recent years, prevalence studies especially population-based ones remain scarce.

This population-based study aimed to identify patients with PAD using the $\mathrm{ABI}$ method and their risk factors in order to determine highrisk patients.

\section{METHODS}

A cross-sectional survey was conducted among the patients at Balcova district of İzmir, which is the third largest city in Turkey. Using systematic random sampling method, 250 participants were chosen among 1,010 registered patients aged over 45 years from a family health center (FHC). The sample size was calculated with a 95\% confidence interval and statistical power of $80 \%$.

Table 1. Distribution of descriptive characteristics of participants, PAD symptoms and ABI values

\begin{tabular}{|c|c|c|}
\hline Characteristic & Category & No. $(\%)$ \\
\hline \multirow[t]{2}{*}{ Gender } & Female & $142(56.8)$ \\
\hline & Male & $108(43.2)$ \\
\hline \multirow[t]{5}{*}{ Age categories (y) } & $45-54$ & $70(28.0)$ \\
\hline & $55-64$ & $78(31.2)$ \\
\hline & $65-74$ & $63(25.2)$ \\
\hline & $75-84$ & $30(12.0)$ \\
\hline & $\geq 85$ & $9(3.6)$ \\
\hline \multirow[t]{16}{*}{ Risk factors } & Diabetes mellitus & $51(20.4)$ \\
\hline & Hypertension & $143(57.2)$ \\
\hline & Cerebrovascular disease & $23(9.2)$ \\
\hline & Renal disease & $6(2.4)$ \\
\hline & Chronic obstructive pulmonary disease & $18(7.2)$ \\
\hline & Coronary artery disease & $29(11.6)$ \\
\hline & Hyperlipidemia & $85(34.0)$ \\
\hline & Smoking & $56(22.4)$ \\
\hline & Family history of heart disease & $123(49.2)$ \\
\hline & Body mass index $\geq 30 \mathrm{~kg} / \mathrm{m}^{2}$ & $94(37.6)$ \\
\hline & Total cholesterol $\geq 200$ mg/dL ( $\mathrm{n}=226)$ & $112(49.6)$ \\
\hline & Low-density lipoprotein cholesterol $\geq 130$ mg/dL $(n=224)$ & $100(44.2)$ \\
\hline & High-density lipoprotein cholesterol <40 mg/dL ( $\mathrm{n}=226)$ & $49(21.7)$ \\
\hline & Triglycerides > 200 mg/dL ( $n=226)$ & $30(13.3)$ \\
\hline & Fasting plasma glucose $\geq 126 \mathrm{mg} / \mathrm{dL}(\mathrm{n}=226)$ & $24(10.6)$ \\
\hline & Hemoglobin A1c $\% \geq 6.6(n=227)$ & $20(8.8)$ \\
\hline \multirow[t]{6}{*}{ Peripheral arterial disease symptoms } & Walking distance <200 m & $30(12.0)$ \\
\hline & Walking distance 200-500 m & $23(9.2)$ \\
\hline & Walking distance $>500 \mathrm{~m}$ & $197(78.8)$ \\
\hline & Lower limb necrosis & $5(0.2)$ \\
\hline & Claudication & $101(40.4)$ \\
\hline & Ischemic rest pain & $48(19.2)$ \\
\hline \multirow[t]{4}{*}{ Ankle-brachial index values } & PAD in mild level $(0.41-0.70)$ & $7(2.8)$ \\
\hline & PAD in moderate level $(0.71-0.89)$ & $37(14.8)$ \\
\hline & PAD total $(A B \mid<0.90)$ & $44(17.6)$ \\
\hline & Non-compressible artery $(\mathrm{ABI}>1.3)$ & $38(15.2)$ \\
\hline
\end{tabular}

$P A D$, peripheral arterial disease; $A B I$, ankle-brachial index. 
Data were collected via face-to-face interviews. A questionnaire, prepared by the researchers, included questions related to patients' demographic data (sex and age), risk factors like comorbid diseases (such as diabetes mellitus [DM], hypertension, cerebrovascular disease [CVD], renal disease, chronic obstructive pulmonary disease [COPD], coronary artery disease [CAD], and hyperlipidemia), smoking habit, family history of heart disease and symptoms of PAD (walking distance, lower limb necrosis, claudication, and ischemic rest pain). Additionally, patients' anthropometric measurements (height and weight values for body mass index [BMI] measured by the researcher) and their laboratory results were also obtained. Claudication was assessed by asking the following question, which refers to the definition of intermittent claudication: "Do you feel leg pain while walking which is relieved when your leg is at rest?" Patients were also asked whether they experienced resting leg pain and pain-free walking distance on a flat road. While evaluating the participants' pain-free walking distance, two separate shopping centers were considered, 200 and $500 \mathrm{~m}$ away from the FHC, as reference points for accuracy of the distance. Patients' last 6-month lipid profile, hemoglobin Alc (HbAlc), and fasting blood glucose values were obtained from the records of the FHC. Patients whose BMI was $30.0 \mathrm{~kg} / \mathrm{m}^{2}$ or higher were considered as obese.

The $\mathrm{ABI}$ is a simple, inexpensive test to diagnose $\mathrm{PAD} .{ }^{8)}$ For ABI calculations, classic Doppler method was used. Both left and right systolic blood pressures of the brachial, dorsalis pedis, and right tibial artery were measured while patients were resting in a supine position. Hand Doppler was used for accurate measurements of the lower limbs. ABI values were calculated by dividing the highest systolic pressure of the ankles by the highest systolic pressure of the arms. ${ }^{9}$ ABI value between 0.90 and 1.30 was considered as normal, $<0.9$ as $\mathrm{PAD}$, and $>1.3$ as noncompressible artery (NCA). ${ }^{10,11)}$ Our study was approved by the University Medical Faculty Ethics Committee (approval no., 2011-01-05). A written informed consent for participation in the study was obtained from all participants.

Data were analyzed using the SPSS software ver. 11.5 (SPSS Inc., Chicago, IL, USA) package program. Besides descriptive analysis, chisquare test, Student t-test, and backward logistic regression analysis were used for comparative analysis. A P-value less than 0.05 was considered significant.

\section{RESULTS}

Descriptive characteristics of participants including PAD symptoms and ABI values are summarized in Table 1 . The plasma lipid parameters of 224-226 patients were obtained from the laboratory data. Based on the measurements, 44 (17.6\%) of participants had PAD, while 38 (15.2\%) had NCA.

\section{Peripheral Arterial Disease}

Distribution of sociodemographic characteristics, risk factors, and

Table 2. Distribution of sociodemographic characteristics, risk factors, and symptoms according to presence and absence of PAD ( $n=250)$

\begin{tabular}{|c|c|c|c|c|}
\hline Characteristic & Category & $\operatorname{PAD}(+)$ & $\operatorname{PAD}(-)$ & P-value \\
\hline \multicolumn{5}{|c|}{ Sociodemographic characteristics } \\
\hline \multirow[t]{2}{*}{ Gender } & Female & $32(72.7)$ & $110(53.4)$ & 0.020 \\
\hline & Male & $12(27.3)$ & $96(46.6)$ & \\
\hline \multirow[t]{5}{*}{ Age categories (y) } & $45-54$ & $6(13.4)$ & $64(31.1)$ & $<0.001$ \\
\hline & $55-64$ & $7(15.9)$ & $71(34.5)$ & \\
\hline & $65-74$ & $15(34.1)$ & $48(23.3)$ & \\
\hline & $75-84$ & $11(25.0)$ & $19(9.2)$ & \\
\hline & $\geq 85$ & $5(11.4)$ & $4(1.9)$ & \\
\hline \multicolumn{5}{|l|}{ Risk factors } \\
\hline \multirow[t]{2}{*}{ Hypertension } & Yes & $33(75.0)$ & $110(53.4)$ & 0.011 \\
\hline & No & $11(25.0)$ & $96(46.6)$ & \\
\hline \multirow[t]{2}{*}{ Cerebrovascular disease } & Yes & $8(18.2)$ & $15(7.3)$ & 0.039 \\
\hline & No & 36 (81.8) & $191(92.7)$ & \\
\hline \multirow[t]{2}{*}{ Triglycerides $(n=226)$} & $\leq 200 \mathrm{mg} / \mathrm{dL}$ & 32 (86.5) & $164(86.5)$ & 1.000 \\
\hline & $>200$ mg/dL & $5(13.5)$ & $25(13.5)$ & \\
\hline \multicolumn{5}{|l|}{ PAD symptoms } \\
\hline \multirow[t]{3}{*}{ Walking distance (m) } & $<200$ & $13(29.5)$ & $17(8.3)$ & $<0.001$ \\
\hline & $200-500$ & $7(15.9)$ & $16(7.8)$ & \\
\hline & $>500$ & $24(54.5)$ & $173(84.0)$ & \\
\hline \multirow[t]{2}{*}{ Lower limb necrosis } & Yes & $3(6.8)$ & $2(1.0)$ & 0.039 \\
\hline & No & 41 (93.2) & $204(99.0)$ & \\
\hline \multirow[t]{2}{*}{ Claudication } & Yes & $32(72.7)$ & 69 (33.5) & $<0.001$ \\
\hline & No & $12(27.3)$ & $137(66.5)$ & \\
\hline \multirow[t]{2}{*}{ Ischemic rest pain } & Yes & $14(31.8)$ & 34 (16.5) & 0.033 \\
\hline & No & 30 (68.2) & $172(83.5)$ & \\
\hline
\end{tabular}


PAD symptoms according to PAD status are shown in Table 2. BMI, renal disease, $\mathrm{COPD}, \mathrm{DM}$, family history of heart disease, $\mathrm{CAD}$, smoking, and lipid, $\mathrm{HbAlc}$, and fasting glucose levels were not statistically different among the participants with and without $\mathrm{PAD}(\mathrm{P}>0.05)$. Of PAD (+) participants, $54.5 \%$ reported claudication-free walking distance over $500 \mathrm{~m}$ and $27.3 \%$ experienced less claudication. These two groups were considered as asymptomatic PAD.

Women were at higher risk of PAD than men $(\mathrm{P}=0.020)$, but not in the regression analysis. Regression analysis revealed two predictors of PAD: age $\geq 65$ years and claudication (Table 3 ).

\section{Non-compressible Artery}

The sociodemographic characteristics, risk factors, and PAD symptom distribution among the NCA (+) and NCA (-) participants were not statistically significant. Increased triglyceride $(\mathrm{TG})$ values $(\mathrm{P}=0.010)$ and male sex $(\mathrm{P}=0.002)$ were significantly associated with NCA (Table 4). Among the participants with NCA, $15.8 \%$ walked a distance of less than $500 \mathrm{~m}, 39.5 \%$ experienced claudication, and $18.4 \%$ experienced ischemic rest pain. Meanwhile, logistic regression analysis showed that male sex, age $<65$ years, and TG $>200 \mathrm{mg} / \mathrm{dL}$ were significantly associated with NCA ABI (Table 5).

\section{Sex Differences}

Of the total participants, 142 were female patients (56.8\%). The mean age of the female participants was $61.8 \pm 11.3$ years old, while that of the male participants was $63.0 \pm 10.9$ years old. With regard to sex, the values for $\mathrm{PAD}$ symptoms and $\mathrm{PAD}$ were higher in women $(\mathrm{P}<0.05)$ except lower limb necrosis $(\mathrm{P}=1.00)$. According to high total and LDL cholesterol levels, there was a statistically significant difference between men (36.8\%; 34.7\%) and women (58.8\%; 51.9\%) with p-values 0.001 and 0.008 , respectively. On the contrary, no significant difference was observed between the values of TGs $(\mathrm{P}=0.692)$. Additionally, with a BMI cutoff point of $30 \mathrm{~kg} / \mathrm{m}^{2}$, the prevalence of obesity was higher among women (49.3\%) than men $(23.1 \%)(\mathrm{P}<0.001)$.
Table 3. Logistic regression for peripheral arterial disease

\begin{tabular}{lcc}
\hline \multicolumn{1}{c}{ Variable } & Odds ratio (95\% confidence interval) & P-value \\
\hline Intercept & 0.037 & \\
Age $(\geq 65 \mathrm{y})$ & $3.517(1.653-7.479)$ & 0.001 \\
Claudication & $3.418(1.581-7.390)$ & 0.002 \\
Gender (female) & $2.014(0.924-4.388)$ & 0.078 \\
\hline
\end{tabular}

Table 5. Logistic regression for non-compressible artery

\begin{tabular}{lcc}
\hline \multicolumn{1}{c}{ Variable } & Odds ratio (95\% confidence interval) & P-value \\
\hline Intercept & 0.058 & \\
Age $(<65 \mathrm{y})$ & $2.559(1.014-6.458)$ & 0.047 \\
Gender (male) & $2.404(1.100-5.252)$ & 0.028 \\
Triglyceride $(>200 \mathrm{mg} / \mathrm{dL})$ & $4.116(1.587-10.676)$ & 0.004 \\
\hline
\end{tabular}

Table 4. NCA distribution according to sociodemographic characteristics, risk factors, and PAD symptoms ( $\mathrm{n}=206)$

\begin{tabular}{|c|c|c|c|c|}
\hline Characteristic & Category & NCA (+) & NCA (-) & P-value \\
\hline \multicolumn{5}{|c|}{ Sociodemographic characteristics } \\
\hline \multirow[t]{2}{*}{ Gender } & Female & $14(36.8)$ & $96(57.18)$ & 0.030 \\
\hline & Male & $24(64.2)$ & $72(42.92)$ & \\
\hline \multirow[t]{5}{*}{ Age categories (y) } & $45-54$ & $13(34.2)$ & $51(30.4)$ & 0.283 \\
\hline & $55-64$ & $17(44.7)$ & $54(32.1)$ & \\
\hline & $65-74$ & $4(10.5)$ & $44(26.2)$ & \\
\hline & $75-84$ & $3(7.9)$ & $16(9.5)$ & \\
\hline & $\geq 85$ & $1(2.6)$ & $3(1.8)$ & \\
\hline \multicolumn{5}{|l|}{ Risk factors } \\
\hline \multirow[t]{2}{*}{ Hypertension } & Yes & $21(55.3)$ & $89(538.0)$ & 0.858 \\
\hline & No & $17(44.7)$ & $79(47.0)$ & \\
\hline \multirow[t]{2}{*}{ Cerebrovascular disease } & Yes & $1(2.6)$ & $14(8.3)$ & 0.314 \\
\hline & No & $37(97.4)$ & $154(91.7)$ & \\
\hline \multirow[t]{2}{*}{ Triglycerides $(n=189)$} & $\leq 200 \mathrm{mg} / \mathrm{dL}$ & $25(71.4)$ & $139(90.3)$ & 0.010 \\
\hline & $>200$ mg/dL & $10(28.6)$ & $15(9.7)$ & \\
\hline \multicolumn{5}{|l|}{ PAD symptoms } \\
\hline \multirow[t]{3}{*}{ Walking distance (m) } & $<200$ & $3(7.9)$ & $14(8.3)$ & 0.996 \\
\hline & $200-500$ & $3(7.9)$ & $13(7.7)$ & \\
\hline & $>500$ & $32(84.2)$ & $141(83.9)$ & \\
\hline \multirow[t]{2}{*}{ Lower limb necrosis } & Yes & 0 & $2(1.2)$ & 1.000 \\
\hline & No & $38(100.0)$ & $166(98.8)$ & \\
\hline \multirow[t]{2}{*}{ Claudication } & Yes & 15 (39.5) & $54(32.1)$ & 0.447 \\
\hline & No & 23 (69.5) & $114(67.9)$ & \\
\hline \multirow[t]{2}{*}{ Ischemic rest pain } & Yes & 7 (18.4) & $27(16.1)$ & 0.809 \\
\hline & No & 31 (81.6) & 141 (83.9) & \\
\hline
\end{tabular}


In this study, $22.4 \%$ of the participants were smokers. Half of the smokers were women. Smoking significantly decreased with age ( $\geq 65$ years old $)$ in both sexes $(\mathrm{P}<0.01)$.

\section{DISCUSSION}

\section{Peripheral Arterial Disease}

In our study, the prevalence of PAD was $17.6 \%$, which was very similar to that reported in other studies in Turkey. ${ }^{6,7)}$ With regard to studies evaluating the prevalence of $\mathrm{PAD}$, age was considered as an important risk factor and was found to have a positive correlation with the prevalence of PAD. ${ }^{12)}$ Moreover, the prevalence of PAD increased with age.

In our study showed that PAD was more prevalent in women (22.5\%) than in men (11.1\%). In terms of sex and prevalence of PAD, it can be inferred that men in general are at more of a disadvantage than women. ${ }^{13)}$ In one study, PAD was found in $3.9 \%$ of men and $3.3 \%$ of women, with a ratio of $1.18 .{ }^{14)}$ Meanwhile, some studies showed no significant relationship between sex and prevalence of PAD. ${ }^{15,16)}$ Other previous studies showed that men had lower prevalence of PAD than women. In Rotterdam study, the prevalence of PAD was $16.9 \%$ among men and $20.5 \%$ among women, with a ratio of $0.82 .{ }^{17}$ ) However, a previous study indicated that although PAD is observed more frequently in elderly men, women more often develop this disease, regardless of age. ${ }^{18)}$ However, previous Turkish studies showed ambiguous sex-related results. In CAREFUL study, no significant difference was observed between sexes in terms of prevalence of low ABI. By contrast, another previous study showed the prevalence of $\mathrm{PAD}$ was higher in men than in women. ${ }^{6,7)}$ In our study, the total cholesterol levels, LDL levels, and BMI were higher among women; as these factors were considered as predictors of $\mathrm{PAD}$, it may not be surprising that women have higher PAD prevalence than men., ${ }^{5,14)}$

Although a strong relationship between DM and low ABI was found in many studies, the association between DM and low ABI lost its significance after conducting multivariate adjustments in the Framingham Heart Study. ${ }^{1,2,14)}$ This association was not revealed in our study too. This may be due to the good blood glucose control among the diabetic participants. Considering the HbAlc values, there was no significant difference between PAD-positive participants and PAD negative participants. On the contrary, data on comorbid diseases were obtained by asking the participants and checking their medications. The fact that the data were obtained directly from the participants, the history may not be reliable, especially pertaining to kidney and heart diseases. This may also explain the absence of association between family history of heart disease and PAD.

Although smoking is a well-known risk factor for PAD, this association was not observed in our study. ${ }^{12,19)}$ This may be due to the change of smoking prevalence among age groups. In our study, $91.1 \%$ of the smokers were aged $<65$ years old. We also found that age is an important risk factor of $\mathrm{PAD}$. In the years to come, a predictable increase in PAD incidence may occur among smokers. In Turkey, there is a need for prospective and well-designed studies on this subject. However, since symptomatic patients with PAD have been advised to quit smoking, it is possible that observational comparisons may be confounded by other factors.

In the study, we evaluated the association between the PAD symptoms and PAD. The frequency of the symptoms among the PAD patients changes in terms of walking distance, necrosis, claudication, and rest pain. The presence of symptoms in patients diagnosed with PAD using $\mathrm{ABI}$ measurement strengthens the diagnosis. On the contrary, more than half of the PAD patients had walking distance more than $500 \mathrm{~m}$, and one-third did not have claudication. These findings also support the diagnostic value of ABI measurement for asymptomatic PAD. These patients' risks for coronary heart disease and prognosis were similar with those diagnosed with symptomatic PAD. ${ }^{20)}$ In 2010, previous study reported that $>200$ million people worldwide have $\mathrm{PAD}{ }^{21)}$ In this context, early diagnosis of PAD is important to prevent negative consequences. In our study, when walking distance was considered as the primary symptom, the asymptomatic PAD rate was $54.5 \%$; when claudication was considered as primary symptom, the asymptomatic PAD rate was $27.3 \%$. In existing literature, estimating the proportion of asymptomatic PAD remained a challenge. ${ }^{22)}$ Based on increasing physician and patient awareness, and the diagnosis of $\mathrm{PAD}$ in primary care, it has become possible to mention the asymptomatic prevalence of $\mathrm{PAD}$ patients.

\section{Non-compressible Artery}

Previous studies showed that an ABI value of $>1.3$ indicates non-elastic or calcified arteries. ${ }^{11)}$ Some investigators consider high ABI as an indicator of PAD since the proportion of PAD is high in this group. ${ }^{23)} \mathrm{Pa}$ tients aged 50-64 years, with risk factors for atherosclerosis like hyperlipidemia, have increased risk of developing PAD. ${ }^{24)}$ In this study, among those with $\mathrm{ABI}$ values $>1.3$, age $<65$ years old, male sex, and higher serum TG levels ( $>200 \mathrm{mg} / \mathrm{dL}$ ) were associated with high ABI values. Additionally, some patients with NCA had PAD symptoms like claudication and ischemic rest pain. A high ABI indicates poorly compressible infra-popliteal vessel, and this finding can mask the detection of $\mathrm{PAD}{ }^{25)}$ As $60 \%-65 \%$ of NCA patients have $\mathrm{PAD}$, those with $\mathrm{PAD}$ symptoms should be referred to undergo imaging studies. ${ }^{26)}$

Conducting the study in a single FHC is one of the limitations of this study; however, as the study population was selected through random sampling, the results of the study can be applied in the general population and is the strength of the study. The samples, which only included the symptomatic patients without a comparison group or which only included those who visited the outpatient clinics, cannot show the risk and may have selection bias (the Berkson's bias). ${ }^{6,7)}$ Although our study population is small, the results of this study may serve as a basis for future meta-analysis. As our aim was to identify PAD patients using the ABI method in order to determine high-risk individuals, early diagnosis, optimum treatment, and referral should be performed among these patients in order to increase their quality of life.

In conclusion, our study showed that PAD diagnosed based on the ABI values was associated with age, sex, TG values, and claudication. 
While low $A B I$ values (PAD) have been associated with age $\geq 65$ years old and claudication, high $\mathrm{ABI}$ values (NCA) were associated with age $<65$ years old, $\mathrm{TG}>200 \mathrm{mg} / \mathrm{dL}$, and male sex.

Although the identified PAD and NCA levels indicates the degree of PAD burden in local primary care, it is obvious that these characteristic differences among age groups need further research using a population-based study.

The reported number of patients with symptomatic PAD is just a 'tip of an iceberg'; similarly, the number of asymptomatic patients remain unclear. Due to the silent nature of this disease, PAD has been considered the least effectively managed major atherosclerotic vascular disorder. ${ }^{27)}$ Almost half of all PAD patients seemed to have some clinical evidence of CAD or CVD, but only a small fraction of patients with PAD are properly diagnosed. ${ }^{28)}$ In this study, it is clear that when considering the rate of $\mathrm{PAD}$, many asymptomatic $\mathrm{PAD}$ patients may be diagnosed only by implementing the ABI method in a more widespread manner.

\section{CONFLICT OF INTEREST}

No potential conflict of interest relevant to this article was reported.

\section{ORCID}

Tolga Vural: https://orcid.org/0000-0002-9396-3089

Makbule Neslişah Tan: https://orcid.org/0000-0002-3262-7815

Mehtap Kartal: https://orcid.org/0000-0002-3424-2513

Azize Dilek Güldal: https://orcid.org/0000-0002-7344-9349

\section{REFERENCES}

1. Chi YW, Jaff MR. Optimal risk factor modification and medical management of the patient with peripheral arterial disease. Catheter Cardiovasc Interv 2008;71:475-89.

2. Zanati SG, Mouraria GG, Matsubara LS, Giannini M, Matsubara BB. Profile of cardiovascular risk factors and mortality in patients with symptomatic peripheral arterial disease. Clinics (Sao Paulo) 2009;64: 323-6.

3. Bergiers S, Vaes B, Degryse J. To screen or not to screen for peripheral arterial disease in subjects aged 80 and over in primary health care: a cross-sectional analysis from the BELFRAIL study. BMC Fam Pract 2011;12:39.

4. Coce F, Metelko Z, Jaksic B, Car N, Pavkovic P. Peripheral arterial disease and diabetes mellitus. Diabetol Croat 2008;37:47-53.

5. Meijer WT, Grobbee DE, Hunink MG, Hofman A, Hoes AW. Determinants of peripheral arterial disease in the elderly: the Rotterdam study. Arch Intern Med 2000;160:2934-8.

6. Karabay O, Karacelik M, Yilik L, Tekin N, Iriz AB, Kumdereli S, et al. Ischemic peripheral arterial disease: a screening survey. Turk Gogus Kalp Damar Cerrahisi Dergisi 2012;20:450-7.

7. Bozkurt AK, Tasci I, Tabak O, Gumus M, Kaplan Y. Peripheral artery disease assessed by ankle-brachial index in patients with established cardiovascular disease or at least one risk factor for atherothrombosis: CAREFUL study: a national, multi-center, cross-sectional observational study. BMC Cardiovasc Disord 2011;11:4.

8. Dachun $\mathrm{Xu}$, Jue Li, Liling Zou, Yawei Xu, Dayi Hu, Pagoto SL, et al. Sensitivity and specificity of the ankle-brachial index to diagnose peripheral artery disease: a structured review. Vasc Med 2010;15:361-9.

9. Watson K, Watson BD, Pater KS. Peripheral arterial disease: a review of disease awareness and management. Am J Geriatr Pharmacother 2006;4:365-79.

10. Matsushita K, Ballew SH, Sang Y, Kalbaugh C, Loehr LR, Hirsch AT, et al. Ankle-brachial index and physical function in older individuals: the Atherosclerosis Risk in Communities (ARIC) study. Atherosclerosis 2017;257:208-15.

11. Jiwakanon S, Adler S, Mehrotra R. Change in ankle-brachial index over time and mortality in diabetics with proteinuria. Clin Nephrol 2012;78: $335-45$.

12. Alzamora MT, Fores R, Baena-Diez JM, Pera G, Toran P, Sorribes M, et al. The peripheral arterial disease study (PERART/ARTPER): prevalence and risk factors in the general population. BMC Public Health 2010;10:38.

13. Hittel N, Donnelly R. Treating peripheral arterial disease in patients with diabetes. Diabetes Obes Metab 2002;4 Suppl 2:S26-31.

14. Murabito JM, Evans JC, Nieto K, Larson MG, Levy D, Wilson PW. Prevalence and clinical correlates of peripheral arterial disease in the Framingham Offspring Study. Am Heart J 2002;143:961-5.

15. Newman AB, Siscovick DS, Manolio TA, Polak J, Fried LP, Borhani NO, et al. Ankle-arm index as a marker of atherosclerosis in the Cardiovascular Health Study. Cardiovascular Heart Study (CHS) Collaborative Research Group. Circulation 1993;88:837-45.

16. Makowsky MJ, McAlister FA, Galbraith PD, Southern DA, Ghali WA, Knudtson ML, et al. Lower extremity peripheral arterial disease in individuals with coronary artery disease: prognostic importance, care gaps, and impact of therapy. Am Heart J 2008;155:348-55.

17. Meijer WT, Hoes AW, Rutgers D, Bots ML, Hofman A, Grobbee DE. Peripheral arterial disease in the elderly: the Rotterdam Study. Arterioscler Thromb Vasc Biol 1998;18:185-92.

18. Selvin E, Erlinger TP. Prevalence of and risk factors for peripheral arterial disease in the United States: results from the National Health and Nutrition Examination Survey, 1999-2000. Circulation 2004;110:73843.

19. Carbayo JA, Divison JA, Escribano J, Lopez-Abril J, Lopez de Coca E, Artigao LM, et al. Using ankle-brachial index to detect peripheral arterial disease: prevalence and associated risk factors in a random population sample. Nutr Metab Cardiovasc Dis 2007;17:41-9.

20. Cimminiello C, Borghi C, Kownator S, Wautrecht JC, Carvounis CP, Kranendonk SE, et al. Prevalence of peripheral arterial disease in patients at non-high cardiovascular risk: rationale and design of the PANDORA study. BMC Cardiovasc Disord 2010;10:35.

21. Fowkes FG, Rudan D, Rudan I, Aboyans V, Denenberg JO, McDermott $\mathrm{MM}$, et al. Comparison of global estimates of prevalence and risk factors for peripheral artery disease in 2000 and 2010: a systematic review and analysis. Lancet 2013;382:1329-40.

22. Keeling AN, Naughton PA, Khalidi K, Ayyoub AS, Kelly CK, Leahy AL, et al. Should incidental asymptomatic angiographic stenoses and occlusions be treated in patients with peripheral arterial disease? J Vasc 
Interv Radiol 2009;20:1133-40.

23. Aboyans V, Ho E, Denenberg JO, Ho LA, Natarajan L, Criqui MH. The association between elevated ankle systolic pressures and peripheral occlusive arterial disease in diabetic and nondiabetic subjects. J Vasc Surg 2008;48:1197-203.

24. Writing Committee Members, Gerhard-Herman MD, Gornik HL, Barrett C, Barshes NR, Corriere MA, et al. 2016 AHA/ACC guideline on the management of patients with lower extremity peripheral artery disease: executive summary. Vasc Med 2017;22:NP1-NP43.

25. Lilly SM, Qasim AN, Mulvey CK, Churchill TW, Reilly MP, Eraso LH. Non-compressible arterial disease and the risk of coronary calcifica- tion in type-2 diabetes. Atherosclerosis 2013;230:17-22.

26. MacDougall AM, Tandon V, Wilson MP, Wilson TW. Oscillometric measurement of ankle-brachial index. Can J Cardiol 2008;24:49-51.

27. Mohler E 3rd, Giri J; ACC; AHA. Management of peripheral arterial disease patients: comparing the ACC/AHA and TASC-II guidelines. Curr Med Res Opin 2008;24:2509-22.

28. Hooi JD, Kester AD, Stoffers HE, Rinkens PE, Knottnerus JA, van Ree JW. Asymptomatic peripheral arterial occlusive disease predicted cardiovascular morbidity and mortality in a 7-year follow-up study. J Clin Epidemiol 2004;57:294-300. 